\section{Canine rheumatoid arthritis characterized by hyperprolactinemia}

\author{
Tohru Kimura \\ Laboratory Animal Science, Joint Faculty \\ of Veterinary Medicine, Yamaguchi \\ University, Japan
}

\section{Abstract}

The senile female dog suffering from rheumatoid arthritis was clinically and clinicopathologically examined. The articular lesions localized in the elbows, stifles, and the carpal and tarsal joints. The dog with clinical signs of arthritis developed draining nodular lesions in the involved joints. The affected joints became swollen, and then serous exudates were observed in their ulcerative lesions. In addition, the dog developed leaks of milk (lactorrhea) in response to suckling stimuli. There were no abnormal values in hematological and blood coagulation profiles. Serum biochemical examinations showed an increase in total protein concentrations. Serum protein electrophoresis confirmed a prominent decrease in albumin and moderate increases in $\beta_{1}, \beta_{2}$ and $\gamma$-globurin. The serum prolactin concentration was apparently higher than that of normal dogs. This affected dog had raised rheumatoid factors and immune complexes. Both antinuclear antibodies and direct Coombs test were positive and serum complement titers and anti DNA antibodies were increased in this dog. In conclusion, the present results revealed that lactorrhea characterized by hyperprolactinemia and autoimmunological profiles was one of important clinical predictors associated with an increased risk of rheumatoid arthritis.

\section{Introduction}

Rheumatoid arthritis of dogs is an uncommon immune-mediateted disease characterized by progressive arthritis. ${ }^{1-6}$ Increased prolactin levels have been described in autoimmune diseases such as systemic lupus erythematous, rheumatoid arthritis, Sjögren syndrome and systemic sclerosis, psoriasis, Behcet's disease and polymyositis. ${ }^{7-9}$ Prolactin is an integral member of the immunoneuroendocrinology network and has some roles in pathogenesis of autoimmune diseases. The frequency of hyperprolactinemia is about onethird of human patients with rheumatoid arthritis. 10
Rheumatoid arthritis in dogs is an uncommon or rare chronic and systemic inflammatory disorder, occurring in approximately 2 per 25,000 dogs. This disorder occurs mainly in small or toy breeds from 8 months to 8 years of age. ${ }^{3,6}$ The author has encountered a case of canine rheumatoid arthritis with hyperprolactinemia in the Experimental Animal Center of Yamaguchi University. There has been a scarcity of reports concerning clinical and clinicopathological findings of this disease. The purpose of this study was to present data that aided in determining its etiology, pathogenesis and pathophysiology. The author performed hematological and serum biochemical examinations in the patient. In addition, the author investigated the immunological changes of this disorder.

\section{Materials and Methods}

\section{Animals}

The female nine-year-old Beagle developed articular lesions with cutaneous ulceration.

The dog was individually housed in stainless steel cage $(85 \times 95 \times 75 \mathrm{~cm})$ in a controlled animal room environment (temperature: $20-25^{\circ} \mathrm{C}$; humidity: 50-70\%). Lightening was controlled to give $12 \mathrm{~h}$ light $(0600-1800)$ and $12 \mathrm{~h}$ dark (1800-0600) per day. The animal room ventilated 10-15 times per hour with fresh air. The animal was fed a commercial dry dog food (Labo D Standard, Nihon Nosan Kogyo Co. Ltd., Yokohama, Japan) and tap water ad libitum.

\section{Blood sample collection}

Blood samples were collected from the cephalic vein of the animal using no anticoagulant. At 30 minutes after collection of blood samples, sera were separated by centrifugation at $1500 \mathrm{~g}$ for 10 minutes for biochemical analysis. For hematological samples, blood was collected into tubes containing $\mathrm{K}_{2}$ EDTA. Additionally, citrated blood samples were immediately analyzed for the blood coagulation examinations.

\section{Hematology}

The following parameters were examined using an automated cell counter F-820 (Sysmex Co. Ltd, Kobe, Japan): red blood cell count (RBC), hemoglobin concentration $(\mathrm{Hb})$, packed cell volume (PCV), mean corpuscular volume (MCV), mean corpuscular hemoglobin (MCH), mean corpuscular hemoglobin concentration (MCHC), white cell count (WBC) and platelet count (PLT).

\section{Blood coagulation}

All blood coagulation values were determined using semi-automated clotting analyzer
Correspondence: Tohru Kimura, Laboratory Animal Science, Joint Faculty of Veterinary Medicine, Yamaguchi University, 1677-1, Yoshida, Yamaguchi, 753-8515, Japan.

Tel.: +81-83-933-5877 - Fax: +81-83-933-5877

E-mail: kimura1@yamaguchi-u.ac.jp

Key words: antinuclear antibodies; hyperprolactinemia, lactorrhea, prolactin, rheumatoid arthritis, rheumatoid factors, serum complement titers.

Conflict of interest: the authors declare no potential conflict of interest.

Received for publication: 9 February 2016. Accepted for publication: 25 April 2016.

This work is licensed under a Creative Commons Attribution NonCommercial 4.0 License (CC BYNC 4.0).

(C) Copyright T. Kimura, 2017

Licensee PAGEPress srl, Italy

Veterinary Science Development 2017; 7:6463

doi:10.4081/vsd.2017.6463

(CA-50, Sysmex Co. Ltd, Kobe, Japan). The following measurements were made in plasma: prothrombin time (PT), fibrinogen concentrations (Fib), activated partial thromboplastin time (APTT).

\section{Serum biochemistry}

The following parameters were measured using a blood chemistry analyzer (Dry Chem 3500: Fuji Film Co. Ltd, Tokyo, Japan): total protein (TP), albumin (Alb), albumin : globulin (A/G) ratio, total bilirubin (T-Bil), urate (UA), creatinin (Crea), blood urea nitrogen (BUN), glucose (Glu), triglycerides (TG), total cholesterol (T-CHO), HDL-cholesterol (HDL-cholesterol), $\beta$-lipoprotein ( $\beta$-lipo), asparate aminotransferase (AST), alanine aminotransferase (ALT), alkaline phosphatase (ALP), lactate dehydrogenase (LDH), creatine kinase (CK), $\gamma$-glutamyl transpeptidase (GGT), amylase (AMS), electrolytes (K, $\mathrm{Ca}, \mathrm{Mg}$ ), iron (Fe) and inorganic phosphorus (IP). In addition, prolactin concentrations were determined using radioimmunoassay.

Serum proteins were separated by electrophoresis on cellulose acetate, quantified densitometrically and expressed as 6 fractions - albumin (Alb), $\alpha_{1^{-}}, \alpha_{2^{-}}, \beta_{1^{-}}, \beta_{2^{-}}$and $\gamma$-globulin - using a rapid Electrophoresis System (Helena Laboratories Co., Ltd., Saitama, Japan).

\section{Immunology}

Immunological examinations were as following: $\mathrm{C}$ reaction proteins (CRP: latex agglutination nephelometry), rheumatoid factors 
(agglutination reaction), immune complexes (agglutination reaction), antinuclear antibodies (ANA: enzyme-linked immunosorbent assay), anti-DNA anitibodies (radioimmunoassay), serum complement titers (immunonephlometry) and direct Coombs test (agglutination reaction).

\section{Results}

\section{Clinical findings}

The dog initially showed depression, listlessness and some reluctance to move about. The first clinical signs were a migratory shifting lameness and soft-tissue swelling around the involved joints. This soft-tissue swelling was detectable as slight joint capsule distention due to synovial fluid effusion (Figure 1). The articular lesions localized in the elbows, stifles, and the carpal and tarsal joints. The dog

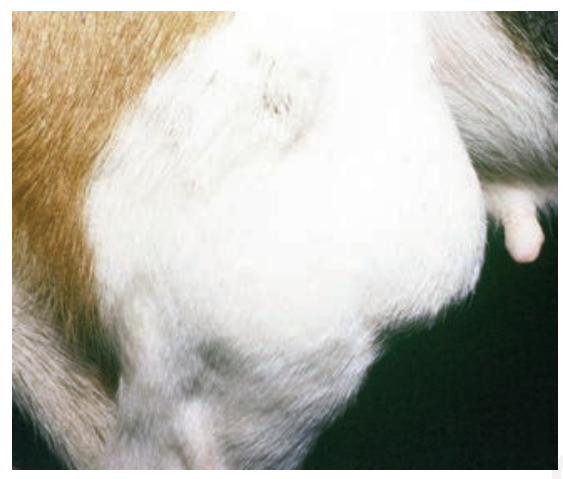

Figure 1. The appearance of rheumatoid arthritis. The soft-tisseu swelling is detected.

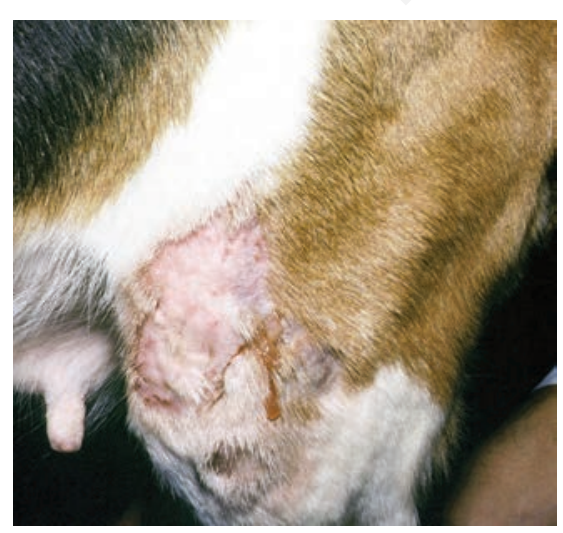

Figure 2. The appearance of rheumatoid arthritis. The swollen and ulcerative joint and serous exudates are observed. with clinical signs of polyarthritis developed ulcerated and draining nodular lesions in the involved joints. The affected joints became swollen, and then serous exudates were observed in the ulcerative lesions (Figure 2). Although the joints did not develop angular deformities, the dog progressively presented a slight stiffness in hind limbs. The dog showed no signs of severe pain referable to the involved joints, while the limb was bearing her weight. In addition, the dog developed leaks of milk (lactorrhea) in response to suckling stimuli (Figure 3).

\section{Hematological findings}

Hematological and serum biochemical profiles are shown in Tables 1 and 2. Hematological results were within in the reference range of Beagles. There were no changes in erythrocytic parameters and mild leukocytosis and thrombocytopenia was not found in the hematological examinations.

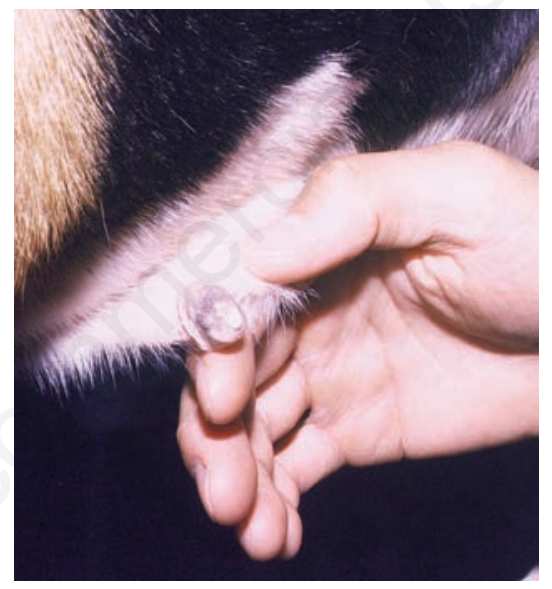

Figure 3. Lactorrhea is seen in the teat.

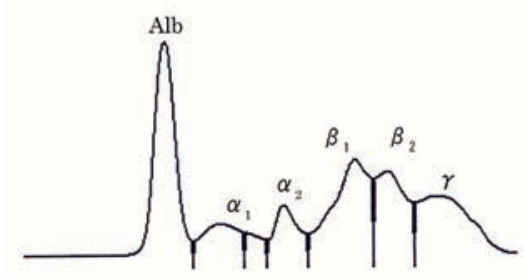

Figure 4. Serum protein electrophoregram. A prominent decrease in albumin and moderate increases in $\beta 1, \beta 2$ and $\gamma$-globurin are observed.

\section{Serum biochemical findings}

Serum biochemical examinations revealed moderate elevations of ALP and LDH activities. There was an increase in total protein concentrations and decrease in albumin concentrations. Consequently, A/G ratio was markedly reduced by approximately half of its reference values.

Serum protein fractions are shown in Table 3 and Figure 4. Serum protein electrophoresis confirmed a prominent decrease in albumin and moderate increases in $\beta_{1}, \beta_{2}$ and $\gamma$ globurin. Lactorrhea was characterized by the enhancement of serum prolactin secretion.

The serum prolactin concentration of this dog with rheumatoid arthritis was apparently higher that of normal dogs.

Table 1. Hematological findings.

\begin{tabular}{lcc} 
Parameters & Units & Values \\
$\mathrm{WBC}$ & $\times 10^{2} / \mu \mathrm{L}$ & 122 \\
$\mathrm{RBC}$ & $\times 10^{4} / \mu \mathrm{L}$ & 545 \\
$\mathrm{Hb}$ & $\mathrm{g} / \mathrm{dL}$ & 11.3 \\
$\mathrm{PCV}$ & $\%$ & 34.7 \\
\hline $\mathrm{MCV}$ & $\mathrm{fl}$ & 63.4 \\
$\mathrm{MCH}$ & $\mathrm{pg}$ & 20.7 \\
\hline $\mathrm{MCHC}$ & $\mathrm{g} / \mathrm{dL}$ & 32.6 \\
$\mathrm{PLT}$ & $\times 10^{4} / \mu \mathrm{L}$ & 39.4 \\
\hline
\end{tabular}

Table 2. Serum biochemical findings.

\begin{tabular}{lcc} 
Parameters & Units & Values \\
TP & $\mathrm{g} / \mathrm{dL}$ & 8.9 \\
Alb & $\mathrm{g} / \mathrm{dL}$ & 2.8 \\
\hline A/G ratio & & 0.45 \\
T-Bil & $\mathrm{mg} / \mathrm{dL}$ & 1.6 \\
\hline UA & $\mathrm{mg} / \mathrm{dL}$ & 1.2 \\
Crea & $\mathrm{mg} / \mathrm{dL}$ & 0.7 \\
\hline BUN & $\mathrm{mg} / \mathrm{dL}$ & 16.1 \\
Glu & $\mathrm{mg} / \mathrm{dL}$ & 85 \\
\hline TG & $\mathrm{mg} / \mathrm{dL}$ & 153 \\
T-Cho & $\mathrm{mg} / \mathrm{dL}$ & 205 \\
\hline HDL-Cho & $\mathrm{mg} / \mathrm{dL}$ & 142 \\
$\beta$-lipo & $\mathrm{mg} / \mathrm{dL}$ & 253.5 \\
\hline AST & $\mathrm{IU}$ & 7.7 \\
ALT & $\mathrm{IU}$ & 5.8 \\
\hline ALP & $\mathrm{IU}$ & 106.5 \\
LDH & $\mathrm{IU}$ & 143.0 \\
\hline CK & $\mathrm{U} / \mathrm{L}$ & 42 \\
GGT & $\mathrm{U} / \mathrm{L}$ & $<10$ \\
\hline AMS & $\mathrm{IU}$ & 2775 \\
K & $\mathrm{mEq} / \mathrm{L}$ & 5.0 \\
\hline Ca & $\mathrm{mg} / \mathrm{dL}$ & 9.57 \\
IP & $\mathrm{mg} / \mathrm{dL}$ & 5.40 \\
\hline Fe & $\mu \mathrm{g} / \mathrm{dL}$ & 64.3 \\
Mg & $\mathrm{mg} / \mathrm{dL}$ & 1.89 \\
\hline Prolactin & $\mu \mathrm{L} / \mathrm{L}$ & 87 \\
\hline & & \\
\hline
\end{tabular}




\section{Blood coagulation systems}

Blood coagulation results are shown in Table 4. Although PT and APTT were within the reference values in our laboratory, fibrinogen concentrations were moderately increased in this patient.

\section{Immune serological findings}

Immune serological variables were shown in Table 5. This affected dog had raised rheumatoid factors and immune complexes. Both antinuclear antibodies (ANA) and direct Coombs test were positive and serum complement titers and anti DNA antibodies were increased in this dog.

\section{Discussion and Conclusions}

The senile female dog suffering from rheumatoid arthritis was clinically and clinicopathologically examined. Rheumatoid arthritis is a chronic systemic autoimmune disease that involves the connective tissues of many organs but primarily assaults the joints. 5 The principle lesions are non-suppurative proliferative synovitis that progressively erode and cover the articular surfaces leading to joint destruction and fibrous ankylosis. ${ }^{6}$ The involved joint can lose its shape and alignment, resulting in pain

Table 3. Electrophoresis (TP=8.9 g/dL).

\begin{tabular}{lcccccc} 
Fractions Alb & \multicolumn{7}{c}{ Globulin } \\
& & $\alpha 1$ & $\alpha 2$ & $\beta 1$ & $\beta 2$ & $\gamma$ \\
$\%$ & 28.2 & 9.3 & 7.2 & 21.0 & 15.7 & 18.6 \\
$\mathrm{~g} / \mathrm{dL}$ & 2.5 & 0.8 & 0.6 & 1.9 & 1.4 & 1.7 \\
\hline
\end{tabular}

Table 4. Blood coagulation tests.

\begin{tabular}{lcc} 
Parameters & Units & Values \\
PT & sec. & 6.7 \\
APTT & sec. & 15.9 \\
\hline Fibrinogen & $\mathrm{mg} / \mathrm{dL}$ & 412 \\
\hline
\end{tabular}

Table 5. Serum immunological findings.

\begin{tabular}{lcc} 
Parameters & Units & Values \\
CRP & $\mathrm{g} / \mathrm{dL}$ & 8.9 \\
Rheumatoid factors & & $(+)$ \\
\hline Immune complexes & $\mu \mathrm{g} / \mathrm{mL}$ & 35.0 \\
ANA & & $(+)$ \\
\hline Anti-DNA anitibodies & $\mathrm{IU} / \mathrm{mL}$ & 160 \\
Serum complement titers & $\mathrm{U} / \mathrm{mL}$ & 46.8 \\
\hline Direct Coombs test & & $(+)$ \\
\hline
\end{tabular}

and loss of movement.3,5,6 Although the signs of this dog affected with rheumatoid arthritis were not severe as compared with those of human patients, the clinical progression of this canine disorder considerably resembled that of human rheumatoid arthritis.

It is well known that the remission in symptoms of rheumatoid arthritis develops during woman pregnancy. ${ }^{11-13}$ Activity of this disease spontaneously tends to recur during the postpartum period with lactation. ${ }^{14}$ Additionally, breast-feeding causes its relapse in woman with rheumatoid arthritis and inflammatory arthritis. ${ }^{15}$ The recent study on the woman patients with rheumatoid arthritis, all of whom had at least 1 pregnancy preceding rheumatoid arthritis onset, showed an association between history of breast-feeding and this disease severity. 16 In the present study, the onset of canine rheumatoid arthritis seemed to be also closely associated with milk ejection reflex (lactation). The present finding showed that lactorrhea was one of important clinical predictors associated with an increased risk of rheumatoid arthritis.

There were no abnormal values in hematological profiles. Neither anemia nor luekocytosis resulting from secondary infection was found in this patient. There were no apparent pathophysiological abnormalities in serum biochemical findings. A various type of serum protein fractions have been found in the electrophoregram of dogs with rheumatoid arthritis. Because rheumatoid arthritis was characterized by severe inflammation of the synovial tissue, the present data demonstrated hypoalbuminemia and moderate increases in fibrinogen, $\beta_{1}, \beta_{2}$ and $\gamma$-globurin. Moderate increases in ALP and LDH activities were in reasonably good agreement with the findings described in previous reports. 6,17

Although canine autoimmune disorders such as rheumatoid arthritis often show an increase in fibrinogens, ${ }^{18}$ blood coagulation examinations indicated that there were no changes in the extrinsic and intrinsic systems of blood coagulation.

A possible determinant involving lactorrhea or lactation is hyperprolactinemia. The association between hyperprolactinemia and rheumatoid arthritis has remained controversial. In some studies, however, the serum level of prolactin was significantly higher in human patients with rheumatoid arthritis. ${ }^{19}$ In other studies, prolactin levels were higher with longer disease evolution and worse functional condition. ${ }^{20}$ It was probable that elevated prolactin levels showed the severity of joint diseases.

In accordance with the occurrence of hyperprolactinemia and galactorrhea with primary hypothyroidism during pregnancy and lactation, hyperprolactinemia occurred primarily in the luteal phase of the estrous cycle of the pri- mary hypothyroidism dogs.21,22 Hyperprolactinemia was associated with disease activity in rheumatoid arthritis.

Serum prolactin concentrations of ANA seropositive patients with juvenile rheumatoid arthritis were significantly higher than those for ANA negative patients. ${ }^{23}$ In this study, the dog with ANA seropositive rheumatoid arthritis also had elevated serum levels of the immunostimulatory hormone prolactin. Because Coombs test determines the presence of antibodies directed against the patient's own erythrocytes, this positive result indicated an autoimmune process of rheumatoid arthritis.

Prolactin plays a role in the development of adjuvant arthritis and restores immunocompetence in experimental rat models. ${ }^{24}$ Endogeneous prolactin is involved in some immunologic early events that lead to the development of adjuvant arthritis. ${ }^{25,26}$ Following the injection of adjuvant, the thymus and activated leucocytes emit signals to the neuroendocrine system and the signals consequently precipitate prolactin secretion. The present results showed that hyperprolactinemia enhanced immune globulin production and provoked positive ANA and rheumatoid factors. Additionally, the present findings showed concomitant increases in anti-DNA anitibodies and serum complement titers. Subsequently, these immunoreactions contributed to the pathogenesis of rheumatoid arthritis in this dog. The interaction between the immunoreactions and neuroendocrine systems was altered in patients with autoimmune diseases such as rheumatoid arthritis. These findings obtained from this study raised the possibility that autoimmune diseases resulted from excessive exposure to serum prolactin.

In conclusion, the present results revealed that lactorrhea characterized by hyperprolactinemia and autoimmunological profiles was one of important clinical predictors associated with an increased risk of rheumatoid arthritis.

\section{References}

1. Heuser W. Canine rheumatoid arthritis. Can Vet J 1980;21:314-6.

2. Carter SD, Bell SC, Bari AS, Bennett D. Immune complexes and rheumatoid factors in canine arthritides. Ann Rheum 1989;48:989-91.

3. Pedersen NC, Morgan JP, Vasseur PB. Canine rheumatoid arthritis. In: Ettinger SJ, Feldman EC eds. Textbook of veterinary internal medicine: diseases of the dog and cat. Vol. 1. 5th ed. Philadelphia: W.B. Saunders Company; 2000. pp. 1879 
4. Gershwin LJ. Veterinary autoimmunity: autoimmune diseases in domestic animals. Ann NY Acad Sci 2007;1109:109-16.

5. Thomson K. Noninfectious (immunemediated) arthritis. In: Maxie MG es. Jubb, Kennedy and Palmer's pathology of domestic animals. Vol. 1, 5th ed. Philadelphia: Elsevier Saunders; 2007. pp. 174-179.

6. Innes JF. Arthritis. In: Tobias KM, Johnston SA, eds. Veterinary surgery: small animal. St Louis: Elsevier Saunders; 2012. pp. 1078-1111.

7. Jara LL, Lavalle C, Fraga A, et al. Prolactin, immunoregulation, and autoimmune diseases. Senin Arthritis Rheum 1991;20:27384.

8. Jara LL, Medina G, Saavedra MA, et al. Prolactin and autoimmunity. Clinic Rev Allerg Immunol 2011;40:50-9.

9. Shelly S, Boaz M, Orbach H. Prolactin and autoimmunity. Autoimmun Rev 2012;11: A465-70.

10. Walker SE, Jacobson JD. Roles of prolactin and gonadotropin-releasing hormone in rheumatic diseases. Rhem Dis North Am 2000;26:713-36.

11. de Man YA, Hazes JMW, van de Geijin FE, et al. Measuring disease activity and functionality during pregnancy in patients with rheumatoid arthritis. Arthritis Rheum 2007;57:716-22.

12. de Man YA, Dolhain RJ, van de Geijin FE, et al. Disease activity of rheumatoid arthritis during pregnancy: results from a nationwide prospective study. Arthritis Rheum 2008;59:1241-8.

13. de Man YA, Dolhain RJEM, Hazes JMW. Disease activity or remission of rheumatoid arthritis before during and following pregnancy. Curr Opin Rheumatol 2014;26:329-33.

14. Sammaritano LR, Bermas BL. Rheumatoid arthritis medications and lactation. Curr Opin Rheumatol 2014;26:354-60.

15. Barrett, JH, Brennan P, Fiddler M, Silman A. Breast-feeding and postpartum relapse in women with rheumatoid and inflammatory arthritis. Arthritis Rheum 2000;43:1010-5.

16. Jorgensen C, Picot MC, Bologna C, Sany J. oral contraception, parity, breast feeding, and severity of rheumatoid arthritis. Ann Rheum Dis 1996;55:94-8.

17. Pedersen NC, Weisner K, Castles JJ, et al. Noninfectious canine arthritis: the inflammatory, nonerosive arthritis. J Am Vet Med Assoc 1976;169:304-10.

18. Bush BM. Total plasma protein. In: Interpretation of Laboratory Results for Small Animal Clinicians. Blackwell Scientific Publications, London, UK. 1991. pp. 238-250.

19. Chikanza IC. The neuroendocrine immunology of rheumatoid arthritis. Clin Rheumatol 1996;10:273-93.

20. Mateo L, Nolla JM, Bonnin MR, et al. High serum prolactin levels in men with rheumatoid arthritis. J Rheumatol 1998; 25:2077-82.

21. Diaz-Espiñeira, MM, Mol JA, Rijinberk, Kooistra HS. Adenohypophyseal function in dogs with primary hypothyroidism and nonthyroidal illness. J Vet Intern Med 2009;23:100-7.

22. Cortese L, Oliva G, Verstegen J, et al. Hyperprolactinaemia and galactorrhoea associated with primary hypothyroidism in a bitch. J Small Anim Pract 1997;38:572-5.

23. McMurray RW, Allen SH, Pepmueller PH, et al. Elevated serum prolactin levels in children with juvenile rheumatoid arthritis and antinuclear antibody seropositivity. J Rheumatol 1995;22:1577-80.

24. van Eden W, Holoshitz J, Cohen I. Antigenic mimicry between mycobacteria and cartilage proteoglycans: the model of adjuvant arthritis. Concepts Immunopathol 1987;4:144-70.

25. Neidhart M. Bromocriptine microcapsules inhibit ornithine decarboxylase activity induced by Freund's complete adjuvant in lymphoid tissues of male rats. Endocrinology 1989;125:2846-52.

26. Neidhart M, Larson DF. Freund's complete adjuvant induces ornithine decarboxylase activity in the central nervous system of male rats and triggers the release of pituitary hormones. J Nueroimmunol 1990;26: 97-105. 